\title{
End-expiratory lung volume assessment using helium and carbon dioxide in an experimental model of pediatric capnoperitoneum
}

\author{
Jacob Karlsson ${ }^{1,2}$ (I) | Gergely H. Fodor ${ }^{3}$ | Andre dos Santos Rocha ${ }^{3}$ | Na Lin $^{3}$ | \\ Walid Habre $^{3,4}$ | Mats Wallin ${ }^{1,5}$ | Magnus Hallbäck ${ }^{5}$ | Ferenc Peták ${ }^{6}$ (D) | \\ Per-Arne Lönnqvist ${ }^{1,2}$
}

${ }^{1}$ Department of Physiology and Pharmacology (FYFA), Eriksson I Lars groupSection of Anesthesiology and Intensive Care, Karolinska Institute, Stockholm, Sweden

${ }^{2}$ Pediatric Perioperative Medicine and Intensive Care, Karolinska University Hospital, Stockholm, Sweden

${ }^{3}$ Unit for Anaesthesiological Investigations, Department of Anesthesiology,

Pharmacology, Intensive Care and

Emergency Medicine, University of Geneva,

Geneva, Switzerland

${ }^{4}$ Pediatric Anesthesia Unit, Geneva Children's Hospital, Geneva, Switzerland

${ }^{5}$ Maquet Critical Care AB, Solna, Sweden

${ }^{6}$ Departmenet of Medical Physics and Informatics, University of Szeged, Szeged, Hungary

\section{Correspondence}

Jacob Karlsson, Department of Physiology and Pharmacology (FYFA), C3, Eriksson I Lars, PA Lönnqvist groupSection of Anesthesiology and Intensive Care, Karolinska Institute, AnestesiochIntensivvårdsavdelningen 171, 76 Stockholm, Sweden.

Email: jacob.karlsson.1@ki.se

\section{Funding information}

This work was supported by the Karolinska Institute and partially by grants from Maquet Critical Care AB, Solna Sweden, and the regional agreement on medical training and research (ALF) between Stockholm County Council and the Karolinska Institute.
Background: Capnoperitoneum during laparoscopy leads to cranial shift of the diaphragm, loss in lung volume, and risk of impaired gas exchange. Infants are susceptible to these changes and bedside assessment of lung volume during laparoscopy might assist with optimizing the ventilation. Thus, the primary aim was to investigate the monitoring value of a continuous end-expiratory lung volume (EELV) assessment method based on $\mathrm{CO}_{2}$ dynamics $\left(\mathrm{EELV}_{\mathrm{CO}_{2}}\right)$ in a pediatric capnoperitoneum model by evaluating the correlation and trending ability against helium washout $\left(\mathrm{EELV}_{\mathrm{He}}\right)$.

Methods: Intra-abdominal pressure (IAP) was randomly varied between 0 , 6, and $12 \mathrm{~mm} \mathrm{Hg}$ with $\mathrm{CO}_{2}$ insufflation, while positive end-expiratory pressure (PEEP) levels of 3,6 , and $9 \mathrm{~cm} \mathrm{H}_{2} \mathrm{O}$ were randomly applied in eight anesthetized and mechanically ventilated chinchilla rabbits. Concomitant $\mathrm{EELV}_{\mathrm{CO}_{2}}$ and $\mathrm{EELV}_{\mathrm{He}}$ and lung clearance index (LCI) were obtained under each experimental condition.

Results: Significant correlations were found between $E_{E L V} \mathrm{CO}_{2}$ and $E E L V_{\mathrm{He}}$ before capnoperitoneum $(r=.85, P<.001)$, although increased IAP distorted this relationship. The negative influence of IAP was counteracted by the application of PEEP 9, which restored the correlation between $\mathrm{EELV}_{\mathrm{CO}_{2}}$ and $\mathrm{EELV}_{\mathrm{He}}$ and resulted in $100 \%$ concordance rate between the methods regarding changes in lung volume. EELV $_{\mathrm{He}}$ and $\mathrm{LCl}$ showed a curvilinear relationship, and an EELV $\mathrm{He}_{\mathrm{H}}$ of approximately $20 \mathrm{~mL} \mathrm{~kg}^{-1}$, determined with a receiver operating characteristic curve, was associated with near-normal $\mathrm{LCl}$ values.

Conclusion: In this animal model of pediatric capnoperitoneum, reliable assessment of changes in EELV based on $\mathrm{EELV}_{\mathrm{CO}_{2}}$ requires an open lung strategy, defined as EELV above approximately $20 \mathrm{~mL} \mathrm{~kg}^{-1}$. 


\section{1 | INTRODUCTION}

Surgical procedures under laparoscopy in children are gaining increasing popularity. ${ }^{1}$ Intra-abdominal insufflation is required to ensure good visualization of the intra-abdominal structures and facilitates surgical dissection. In routine clinical practice, carbon dioxide $\left(\mathrm{CO}_{2}\right)$ is the most common gas used to provide pneumoperitoneum. While studies have demonstrated the safety of $\mathrm{CO}_{2}$ to insufflate the abdomen, ${ }^{2}$ the procedure still poses challenges regarding $\mathrm{CO}_{2}$ absorption and clearance. On one hand, insufflation per se provides an extra $\mathrm{CO}_{2}$-load to the patient, since a substantial portion of the insufflated $\mathrm{CO}_{2}$ can be absorbed into the circulation. ${ }^{3,4}$ On the other hand, the elimination of $\mathrm{CO}_{2}$ by the lung is jeopardized by the reduced lung volume resulting from the cranial shift of the diaphragm, which is caused by the increase in intra-abdominal pressure (IAP). ${ }^{5}$ Furthermore, laparoscopic surgery requires general anesthesia with administration of muscle relaxants, which further contributes to a reduced lung volume. ${ }^{6}$ Therefore, it would be highly desirable to be able to continuously monitor the lung volume and to adapt the ventilation strategy during laparoscopy. In accordance with the open lung concept, ${ }^{7}$ application of an adequate positive end-expiratory pressure (PEEP) level would overcome the detrimental effects of capnoperitoneum on the lung volume and, thereby, reduce ventilation in homogeneity.

Conventional assessments of end-expiratory lung volume (EELV) by the multiple breath washout technique (MBWT) require the use of foreign gases (eg, helium, nitrogen, sulfur hexafluoride), which makes this technology impractical to use for routine respiratory monitoring during anesthesia and intensive care. However, a recent approach based on capnodynamics may provide added value regarding continuous assessment and in particular trending of EELV in these settings. ${ }^{8}$

Thus, the primary aim of the present experimental study was to investigate if the correlation and trending ability between conventional MBWT and capnodynamic lung volume measurements is preserved during capnoperitoneum, using IAP and PEEP levels that are commonly applied in clinical pediatric practice.

\section{2 | MATERIALS AND METHODS}

\section{1 | Animal preparation}

The study was performed at the Unit for Anesthesiological Investigations of the University of Geneva, Geneva, Switzerland. The protocol was approved by the Ethics Committee of the Canton of Geneva (GE/4/17, 2 February 2017) for experimental research.

The animals and protocol used in the current investigation were part of another study, analyzing the optimal PEEP required for adequate $\mathrm{CO}_{2}$ homeostasis in the same setting, where the anesthetic and surgical procedures are described in further detail. ${ }^{9}$

Briefly, eight adult chinchilla rabbits (median weight $3.7 \mathrm{~kg}$, range 3.6-3.9 kg), purchased from the animal farm of the University of Geneva, were anesthetized and mechanically ventilated in

\section{Editorial Comment}

Laparoscopy and peritoneal insufflation in infants can present a challenge for optimalization of ventilation. In this large animal model of varying intra-abdominal pressure by carbon dioxide insufflation and PEEP, end-expiratory lung volumes were assessed using an advanced gas dilution technique.

volume-control mode (tidal volume $7 \mathrm{~mL} \mathrm{~kg}^{-1}$ ) with $\mathrm{FiO}_{2} 0.4$ and a respiratory rate adjusted to reach end-tidal normocapnia (5.5-6.0 kPa). The ventilator was equipped with additional software to generate the breathing pattern required for $\mathrm{EELV}_{\mathrm{CO}_{2}}$ determination (Servo I, Maquet Critical Care).The carotid artery was cannulated for blood sampling and an intra-abdominal $\mathrm{CO}_{2}$ insufflation system (Electronic Endoflator, Karl Storz) was inserted in the abdominal cavity to generate the various IAP levels.

\section{2 | EELV $_{\mathrm{He}}$ measurements using helium washout}

EELV $_{\mathrm{He}}$ was determined by a helium (He) MBWT (EXHALYZER D; ECO Medics AG) procedure that has been validated and described in detail in previous publications. ${ }^{8,10}$

Briefly, an ultrasonic flow meter (Spiroson Scientific; ECO Medics $A G)$ was inserted between the endotracheal tube connector and the ventilator circuit to measure changes in density of the respiratory gas. Helium was dispensed into the inspiratory limb of the ventilatory circuit and, at an end-inspiratory concentration of $4 \%-5 \%$, and recording was started. The He flow was then interrupted, and the washout dilution of the tracer gas was recorded. ELVV $_{\mathrm{He}}$ was calculated from the changes in the He concentration during the washout phase by special software, (Spiroware, V1.4.3, ECO Medics AG) as previously described. ${ }^{8,10}$ The instrumental dead space between the capnograph and point of $\operatorname{EELV}_{\mathrm{He}}$ measurement $(3.8 \mathrm{~mL})$ was subtracted from the reported EELV $_{\mathrm{He}}$ values.

In addition to EELV recordings, the MBWT also enables assessment of the lung clearance index $(\mathrm{LCl})$, a surrogate of ventilation homogeneity and a sensitive marker of small airway collapse. ${ }^{11} \mathrm{LCl}$ was calculated as the number of lung volume turnovers required to decrease the He concentration to $1 / 40$ th of the starting value. ${ }^{12}$

\subsection{Assessment of $\mathrm{EELV}_{\mathrm{CO}_{2}}$ using dynamic capnography}

$\mathrm{EELV}_{\mathrm{CO}_{2}}$ was calculated continuously using data from standard measurements of end-tidal $\mathrm{CO}_{2}$ concentration with a mainstream infrared $\mathrm{CO}_{2}$ sensor (Capnostat-3, Respironics Inc) inserted between the endotracheal tube connector and the ultrasonic flow meter. Ventilation airflow was recorded by the regular Y-piece flow sensor of the Servo 
I ventilator. The tidal $\mathrm{CO}_{2}$ elimination rate $\left(\mathrm{VCO}_{2} \mathrm{~mL} \mathrm{~min}^{-1}\right)$ was calculated from volumetric capnography using data from the ventilator and main stream capnograph, as previously described. ${ }^{13}$ The principle for calculating EELV $\mathrm{CO}_{2}$ is based on the molar balance of $\mathrm{CO}_{2}$ described in Equation 1.

$\operatorname{EELV}_{\mathrm{CO}_{2}}\left(\mathrm{~F}_{\mathrm{A}} \mathrm{CO}_{2}^{n}-\mathrm{F}_{\mathrm{A}} \mathrm{CO}_{2}^{n-1}\right)=\mathrm{EPBF} \cdot \Delta t^{n} \cdot\left(\mathrm{C}_{\mathrm{V}} \mathrm{CO}_{2}-\mathrm{C}_{\mathrm{C}} \mathrm{CO}_{2}^{n}\right)-\mathrm{VTC} \mathbb{O}_{2}^{n}$.

$\mathrm{EELV}_{\mathrm{CO}_{2}}, \mathrm{EELV} \mathrm{CO}{ }_{2}$ (liter) containing $\mathrm{CO}_{2}$ at the end of expiration; EPBF, effective pulmonary blood flow (liter $\left.\min ^{-1}\right) ; n$, current breath; $n-1$, previous breath; $\mathrm{F}_{\mathrm{A}} \mathrm{CO}_{2}$, alveolar $\mathrm{CO}_{2}$ fraction; $\mathrm{C}_{\mathrm{V}} \mathrm{CO}_{2}$, venous $\mathrm{CO}_{2}$ content (liter ${ }_{\text {gas }}$ liter ${ }_{\text {blood }}{ }^{-1}$ ); $\mathrm{C}_{\mathrm{C}} \mathrm{CO}_{2}{ }_{2}$, lung capillary $\mathrm{CO}_{2}$ content (calculated from $\mathrm{F}_{\mathrm{A}} \mathrm{CO}_{2}$ ); $\mathrm{VTCO}_{2}{ }_{2}$, volume (liter) of $\mathrm{CO}_{2}$ eliminated by the current, $n$ th, breath; $\Delta t^{n}$, current breath cycle time (min).

The capnodynamic equation above is described in further detail in our previous publications. ${ }^{8,10,14,15}$ In short, the equation makes it possible to quantify $E E L V_{\mathrm{CO}_{2}}$, which is the EELV containing $\mathrm{CO}_{2}$ as measured by the capnodynamic method, including the airway volume up to the site of the $\mathrm{CO}_{2}$ sensor and the $\mathrm{CO}_{2}$ dissolved in lung tissue and lung capillary blood. EELV $\mathrm{CO}_{2}$ is therefore by definition a separate measurand, distinct from $\mathrm{EELV}_{\mathrm{He}}$, and absolute values will thus not necessarily equal values obtained with inert gas dilution. However, $\mathrm{EELV}_{\mathrm{CO}_{2}}$ has shown strong correlation with $\mathrm{EELV}_{\mathrm{He}}$ as well as the ability to generate absolute values of the same order of magnitude as inert gas dilution when a sufficient PEEP level is applied. . $^{8,10,15}$

All values are reported at body temperature and pressure, saturated conditions. The mathematical analysis required for the continuous EELV $\mathrm{CO}_{2}$ calculation was performed in Matlab (Matlab ${ }^{\mathrm{TM}}$, The Mathworks Inc).

\section{4 | Study protocol}

Following instrumentation, the rabbits were allowed a 15-minute stabilization period prior to the initiation of the protocol. A lung recruitment maneuver using PEEP $3 \mathrm{~cm} \mathrm{H}_{2} \mathrm{O}$ and tidal volume of
$14 \mathrm{~mL} \mathrm{~kg}^{-1}$ was performed while applying two consecutive periods of 10 seconds inspiratory hold in order to standardize the lung volume. $^{8}$ This process was done after surgical instrumentation and prior to each change in PEEP.

Figure 1 summarizes the scheme of the experimental protocol. Initially, baseline recordings were made at an IAP of $0 \mathrm{~mm} \mathrm{Hg}$ and a PEEP of $3 \mathrm{~cm} \mathrm{H}_{2} \mathrm{O}$. The IAP was then increased to either 6 or $12 \mathrm{~mm} \mathrm{Hg}$ randomly and measurements were repeated twice after going back to IAP $0 \mathrm{~mm} \mathrm{Hg}$. Another randomization was applied for the PEEP level, which was either 6 or $9 \mathrm{~cm} \mathrm{H}_{2} \mathrm{O}$ and the entire procedure was repeated. $\mathrm{EELV}_{\mathrm{CO}_{2}}$ and $\mathrm{EELV}_{\mathrm{He}}$ recordings were performed 3 minutes after the target IAP level was established. $\mathrm{LCI}$ and $\mathrm{EELV}_{\mathrm{He}}$ were obtained from the average of two recordings. $E E L V_{\mathrm{CO}_{2}}$ values represent an average over 60 seconds preceding the He washout.

Following completion of the protocol, the animals were sacrificed with an overdose of iv sodium thiopental $\left(100 \mathrm{mg} \mathrm{kg}^{-1}\right)$.

\subsection{Statistical analysis}

Data are presented as mean \pm half-width of the $95 \%$ confidence interval. Normality of the data distribution was verified with the Shapiro-Wilk K2 test. Logarithmic transformation was performed to ensure normality when needed ( $\mathrm{LCl}$ and mean arterial pressure, MAP). Two-way repeated measure analysis of variation with subsequent Bonferroni multiple comparison tests was used to detect significant changes in the parameters measured by considering PEEP level and IAP as within subject factors. Correlation analyses were performed using Pearson's correlation tests. The ability of $\mathrm{EELV}_{\mathrm{CO}_{2}}$ to track changes in EELV was assessed by calculating the concordance (the proportion of measurements that change in the same direction when two techniques are compared) for $E E L V_{\mathrm{CO}_{2}}$ and $E E L V_{\mathrm{He}}$ and the concordance is displayed in a four quadrant plot with a $15 \%$ exclusion zone. ${ }^{16}$ A priori, a concordance rate of $>92 \%$ was considered clinically useful. ${ }^{16}$
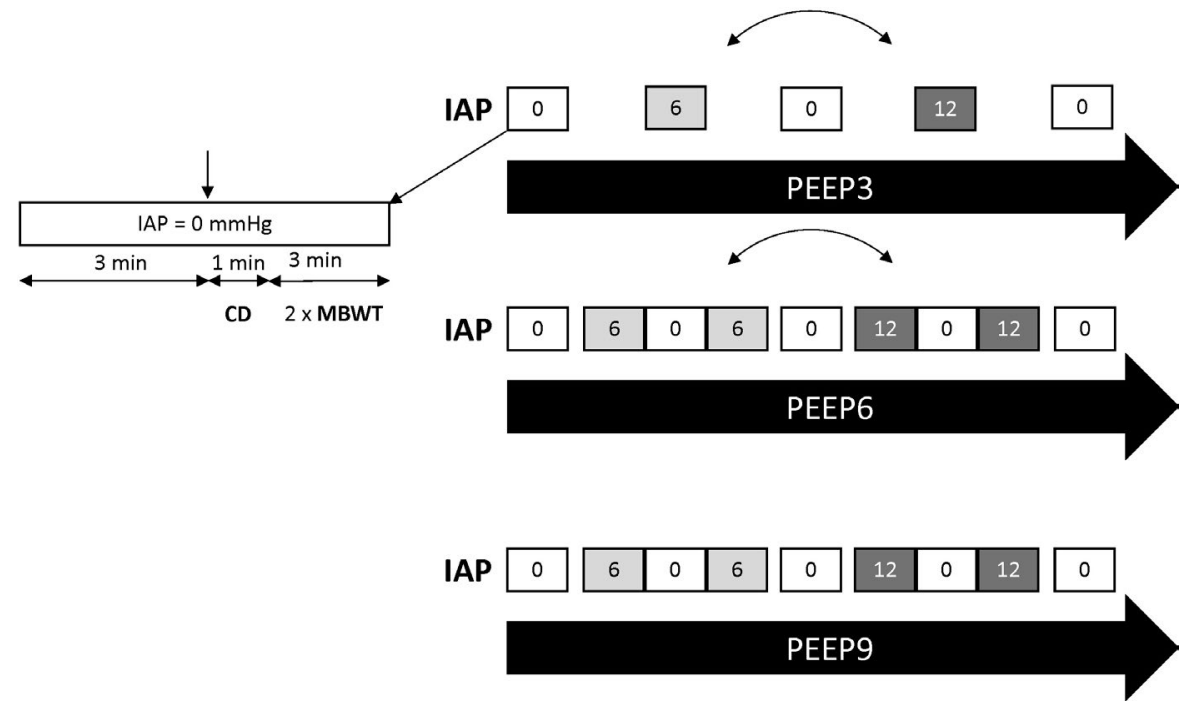

FIGURE 1 Scheme of the experimental protocol. Lung volume assessments by the multiple breath washout technique (MBWT) and capnodynamics (CD) were performed at positive end-expiratory pressure (PEEP) levels of 3,6 , and $9 \mathrm{~cm}$ $\mathrm{H}_{2} \mathrm{O}$ while intra-abdominal pressure (IAP) of 0,6 , and $12 \mathrm{~mm} \mathrm{Hg}$. The PEEP-IAP sequence was pre-randomized. Blood gas and cardiac output measurements associated with another study were done before the $C D$ recording 
Receiver operating characteristics (ROC) curve analysis was performed to determine the threshold for $\mathrm{EELV}_{\mathrm{He}}$ at which significant ventilation heterogeneity developed. Based on the literature, an $\mathrm{LCl}$ index of 7 is considered the upper limit of normality in healthy lungs. ${ }^{12}$ The threshold value in EELV $_{\mathrm{He}}$ was defined as the value having the highest Youden index (specificity + sensitivity - 1).

Based on previous data, ${ }^{8}$ a sample size of eight animals was required for a preset minimum difference of $20 \%$ between the methods, assuming a standard deviation of differences of $5 \mathrm{~mL}$ with a set $\alpha$ error of 0.05 and a power of $80 \%$. GraphPad Prism (version 7.0, GraphPad Software) and SigmaPlot (version 14.0, Systat Software Inc) were used for the statistical analyses, and the statistical tests were performed with a significance level of $P<.05$.

\section{3 | RESULTS}

All eight animals survived the experiment. Data from one rabbit are missing for PEEP $9 \mathrm{~cm} \mathrm{H}_{2} \mathrm{O}$ due to technical sampling problems.

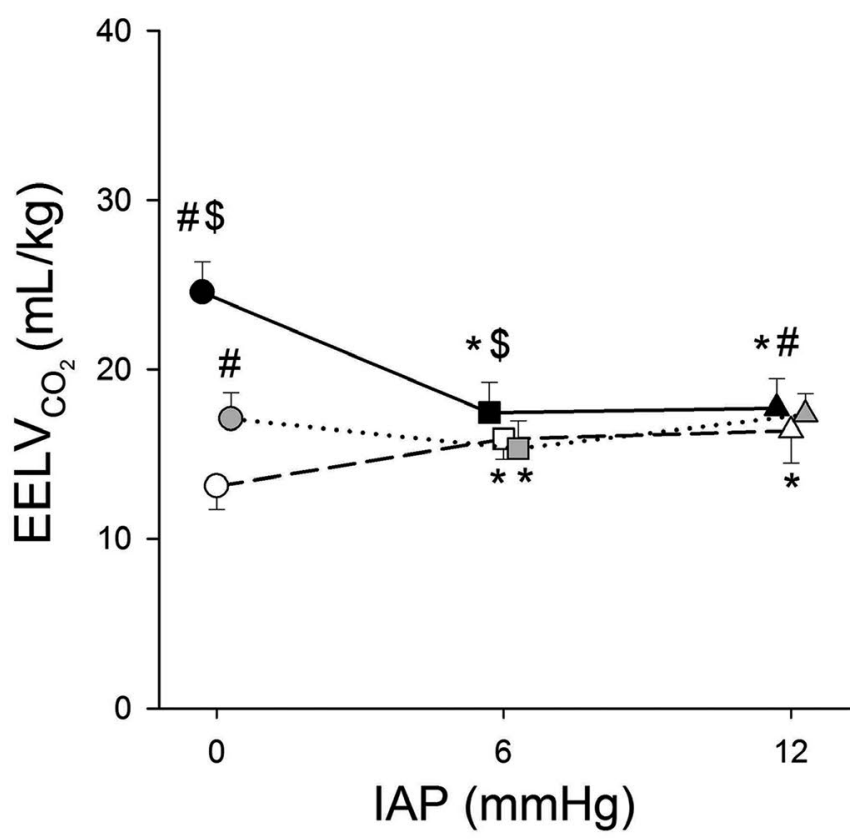

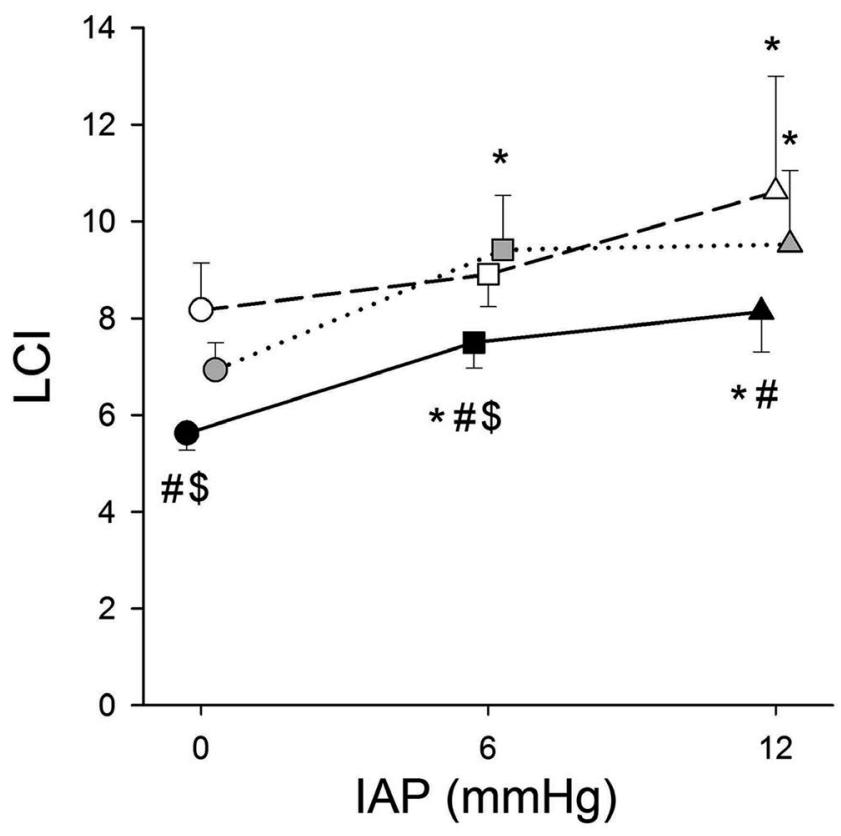

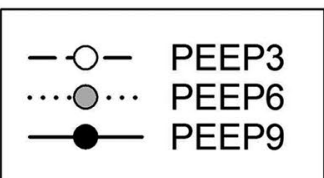

FIGURE 2 Lung volume and heterogeneity parameters obtained by using multiple breath washout technique $\left(\mathrm{EELV}_{\mathrm{He}}, \mathrm{LCl}\right)$ and capnodynamics $\left(\mathrm{EELV}_{\mathrm{CO}_{2}}\right)$ as a function of intra-abdominal pressure (IAP). Open symbols: measurements under positive end-expiratory

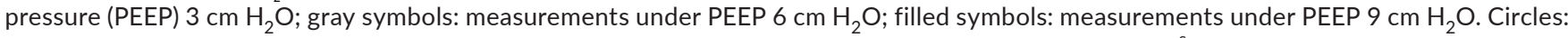
IAP $0 \mathrm{~mm} \mathrm{Hg}$; squares: IAP $6 \mathrm{~mm} \mathrm{Hg}$; triangles: IAP $\mathrm{mm} \mathrm{Hg} \mathrm{cm} \mathrm{H} \mathrm{H}_{2} \mathrm{O}$. ${ }^{*} P<.05$ vs IAP 0 within a PEEP level; ${ }^{\S} \mathrm{P}<.05$ vs IAP 6 within a PEEP level; ${ }^{\#} P<.05$ vs PEEP3 within an IAP level; ${ }^{\$} P<.05$ vs PEEP6 within an IAP level 
The effects of changes in IAP and PEEP on the primary outcome variables are summarized in Figure 2 as a function of IAP. As expected, elevating IAP led to significant decreases in EELV ${ }_{\mathrm{He}}$ $(P<.001)$, which was compensated by elevating PEEP to 6 and $9 \mathrm{~cm}$ $\mathrm{H}_{2} \mathrm{O}(P<.001)$. These changes were only reflected in EELV $\mathrm{CO}_{2}$ at the highest PEEP level. In addition, this was the only PEEP level showing a significant positive correlation between $\mathrm{EELV}_{\mathrm{CO}_{2}}$ and $E E L V_{\mathrm{He}}$ for pooled data from all IAP levels $(r=.72, P<.0001)$.

Elevating PEEP at all IAP levels improved $\mathrm{LCI}(P<.001)$, although without completely counteracting the deleterious effect of high IAP on ventilation homogeneity.

Relationships between the data obtained from the two techniques for lung volume assessment are shown in Figure 3. At IAP $0 \mathrm{~mm} \mathrm{Hg}, \mathrm{EELV}_{\mathrm{CO}_{2}}$ and $\mathrm{EELV}_{\mathrm{He}}$ showed a strong and highly significant correlation for pooled data obtained at all PEEP levels $(r=.85$, $P<.0001)$. Increasing IAP to $6 \mathrm{~mm} \mathrm{Hg}$ diminished this correlation markedly ( $r=.47, P<.03$ ), whereas no significant correlation was observed between these lung volume indices when IAP was further increased to $12 \mathrm{~mm} \mathrm{Hg}(r=-0.11, P=.61)$. Strong correlations were obtained between EELV $\mathrm{He}_{\mathrm{He}}$ and LCl independent of the IAP and PEEP levels $(r=-0.74,-.69$ and -.85 for IAP 0, 6 and $12 \mathrm{~mm} \mathrm{Hg}$, respectively, $P<.0001$ for all). A significant correlation between $\mathrm{EELV}_{\mathrm{CO}_{2}}$ and $\mathrm{LCl}$ was only apparent at the highest PEEP $(r=-.67, P<.001)$, while applying PEEP levels of 6 and $3 \mathrm{~cm} \mathrm{H} \mathrm{H}_{2} \mathrm{O}$ led to a reduction $(r=-.46, P<.03)$ and abolishment $(r=.16, P=.46)$ of this correlation, respectively. $\mathrm{ROC}$ analysis of $\mathrm{EELV}_{\mathrm{He}}$ and $\mathrm{LCl}$ relationship revealed an area under the curve of 0.95 and a threshold of $19.1 \mathrm{~mL} \mathrm{~kg}^{-1}$, rounded to approximately $20 \mathrm{~mL} \mathrm{~kg}^{-1}$, for $\mathrm{EELV}_{\mathrm{He}}$, at which point $\mathrm{LCl}$ increases above the normal value of 7 .

Graphs for the concordance rate between $\mathrm{EELV}_{\mathrm{CO}_{2}}$ and $\mathrm{EELV}_{\mathrm{He}}$ are presented in Figure 4. These figures depict the direction and magnitude of change in the two lung volume assessments during the period in which IAP was altered. This concordance rate between $\mathrm{EELV}_{\mathrm{CO}_{2}}$ and $\mathrm{EELV}_{\mathrm{He}}$ was $8 \%, 63 \%$, and $100 \%$ for PEEP 3, 6, and 9, respectively, when considering a $15 \%$ exclusion zone.

\section{4 | DISCUSSION}

The present study assessed the lung volume changes obtained with inert gas washout and continuous capnodynamic estimates at different IAP and PEEP levels. The capnodynamic technique of measuring EELV during capnoperitoneum was only able to adequately detect changes due to alterations in IAP when a PEEP of $9 \mathrm{~cm} \mathrm{H}_{2} \mathrm{O}$ was applied. The ability for EELV $\mathrm{CO}_{2}$ to track changes in EELV increased with increased PEEP levels, resulting in a $100 \%$ concordance rate

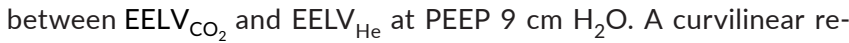
lationship was found between $\mathrm{EELV}_{\mathrm{He}}$ and $\mathrm{LCl}$ also during capnoperitoneum, indicating that EELV values of approximately $20 \mathrm{~mL} \mathrm{~kg}^{-1}$ are necessary to result in LCl values near normal and potentially indicative of homogenous lung conditions. Furthermore, strong correlations were found between the two lung volume measurement techniques before inflating the abdomen with $\mathrm{CO}_{2}$, whereas this relationship weakened with elevating IAP.

The significant correlation between the two lung volume measurements in the absence of capnoperitoneum is in agreement with previous findings under similar experimental conditions. ${ }^{8,10}$

Interestingly, we observed that, after inflating the abdomen with a moderate pressure, the relationship between $E E L V_{\mathrm{He}}$ and $E E L V_{\mathrm{CO}_{2}}$ weakened, and applying a high IAP resulted in uncoupling of these lung volume indices. This phenomenon was also manifested in a very poor concordance rate at the lowest PEEP level since increasing IAP
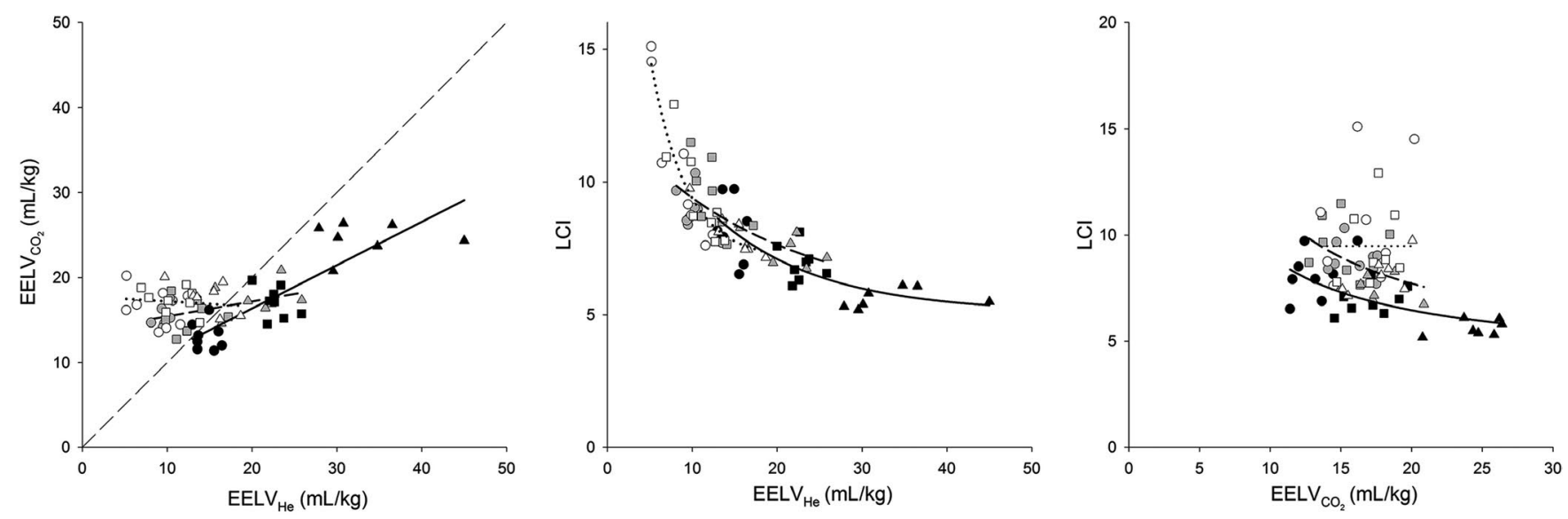

- IAPO-PEEP3 0 IAP6-PEEP3 $\bigcirc$ IAP12-PEEP3

- IAPO-PEEP6 $\square$ IAP6-PEEP6 $\square$ IAP12-PEEP6

TAP0-PEEP9 $\triangle$ IAP6-PEEP9 $\triangle$ IAP12-PEEP9

FIGURE 3 Relationships between lung volume and heterogeneity parameters obtained by using multiple breath washout technique $\left(E_{E L V} \mathrm{He}, \mathrm{LCl}\right)$ and capnodynamics $\left(\mathrm{EELV}_{\mathrm{CO}_{2}}\right)$. Open symbols: measurements under positive end-expiratory pressure $(\mathrm{PEEP}) 3 \mathrm{~cm} \mathrm{H}_{2} \mathrm{O}$; gray symbols: measurements under PEEP $6 \mathrm{~cm} \mathrm{H}_{2} \mathrm{O}$; filled symbols: measurements under PEEP $9 \mathrm{~cm} \mathrm{H}_{2} \mathrm{O}$. Circles: IAP $0 \mathrm{~mm} \mathrm{Hg}$; squares: IAP $6 \mathrm{~mm} \mathrm{Hg}$; triangles: IAP $12 \mathrm{~mm} \mathrm{Hg}$. Thick continuous, dashed and dotted lines denote linear regression curves for pooled data at IAP levels of 0,6 , and $12 \mathrm{~mm} \mathrm{Hg}$, respectively. Thin dashed line on left panel: line of identity 

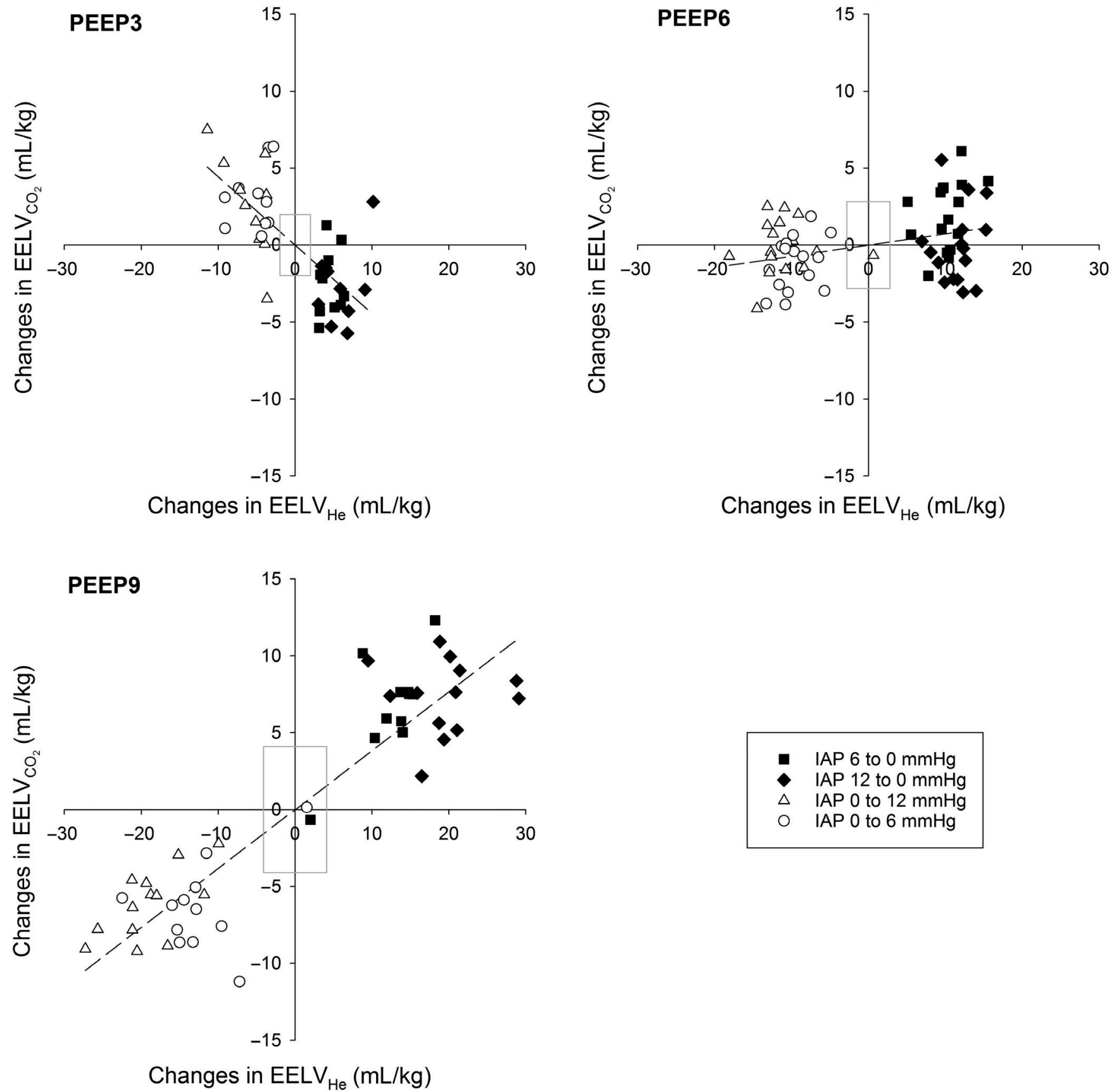

- IAP 6 to $0 \mathrm{mmHg}$

- IAP 12 to $0 \mathrm{mmHg}$

$\triangle \quad$ IAP 0 to $12 \mathrm{mmHg}$

O IAP 0 to $6 \mathrm{mmHg}$

FIGURE 4 Concordances between changes in EELV $\mathrm{CO}_{2}$ and EELV $\mathrm{He}_{\mathrm{He}}$ at different PEEP levels of 3, 6, and $9 \mathrm{~cm} \mathrm{H}_{2} \mathrm{O}$. Open circles: changes obtained when IAP was increased from 0 to $6 \mathrm{~mm} \mathrm{Hg}$. Open triangles: increases in IAP from 0 to $12 \mathrm{~mm} \mathrm{Hg}$. Black squares: reduction in IAP from 6 to $0 \mathrm{~mm} \mathrm{Hg}$. Black diamonds: reduction in IAP from 12 to $0 \mathrm{~mm} \mathrm{Hg}$. Dashed lines: linear regression curves. Gray squares: $15 \%$ exclusion ranges. IAP: intra-abdominal pressure

led to opposite changes in the majority of the cases. Several factors may contribute to the development of this discrepancy at high IAP associated with low PEEP. First, the solubility coefficient of $\mathrm{CO}_{2}$ is high (21 times that of $\mathrm{O}_{2}$ ), which may result in a substantial diffusion of the gas with subsequent accumulation within the lung tissue itself. This may have biased the EELV $\mathrm{CO}_{2}$, and this conclusion is supported by a significant correlation between $\mathrm{EELV}_{\mathrm{CO}_{2}}$ and $\mathrm{CO}_{2}$ excretion at IAP $12 \mathrm{~mm} \mathrm{Hg}$ ( $r=.44, P=.036$, data not shown). Secondly, high IAP in the presence of low to moderate PEEP may have resulted in airway closure and atelectasis development that were detected by $E E L V_{\mathrm{He}}$. However, the opposite changes exhibited in $\mathrm{EELV}_{\mathrm{CO}_{2}}$ may be attributed to the increased lung clearance in $\mathrm{CO}_{2}$ following capnoperitoneum. Applying high PEEP homogenized the lung by reopening atelectatic areas and, thereby, allowing $\mathrm{CO}_{2}$-based capnodynamic estimates to be reliable.

In previous studies we have shown a curvilinear relationship between $\mathrm{EELV}_{\mathrm{He}}$ and $\mathrm{LCl}^{8}{ }^{8}$ This curvilinear relationship was also found to be preserved during capnoperitoneum (Figure 3). From this 
relationship, we were able to define a threshold of approximately $20 \mathrm{~mL} \mathrm{~kg}^{-1}$ for EELV as potentially indicative of homogenous open lung conditions.

Only at PEEP 9 did EELV $\mathrm{He}_{\mathrm{He}}$ and EELV $\mathrm{CO}_{2}$ reach values above the threshold (approximately $20 \mathrm{~mL} \mathrm{~kg}^{-1}$ ), which are close to normal EELV values of approximately $25 \mathrm{~mL} \mathrm{~kg}^{-1} \cdot{ }^{17,18}$ Furthermore, only at these lung volumes did the $\mathrm{LCl}$ values suggest homogenous lung conditions. In the current animal model, these conditions were reached by the use of PEEP $9 \mathrm{~cm} \mathrm{H} 2 \mathrm{O}$. It is, however, important to emphasize that this PEEP level naturally can differ depending on situation, species, and subjects. Thus, it can be speculated that, under clinical circumstances, PEEP should be adjusted to result in an EELV $\mathrm{CO}_{2}$ close to the normal EELV for the subject's actual weight and age. A normal EELV should ensure acceptable lung homogeneity, allowing $E E V_{\mathrm{CO}_{2}}$ to be used in a clinically useful fashion for continuous lung volume measurements and trending. ${ }^{19}$ Although the data from this animal study cannot be immediately transposed to the human setting, it indicates that PEEP needs to be adjusted in an adequate manner to counteract the effects of increased IAP, thus, resulting in using higher PEEP values than usually used in routine pediatric anesthesia. However, this hypothesis obviously needs to be validated in future studies.

In the present study, we did not observe a decline in MAP when PEEP levels were elevated from 3 to $9 \mathrm{~cm} \mathrm{H}_{2} \mathrm{O}$ (Table 1), suggesting that PEEP had no deleterious hemodynamic consequences in this model. Contrary, increasing IAP at a given PEEP led to a mild but significant increase in MAP. This finding is in agreement with previous experimental results ${ }^{20}$ and can be explained by the increases in systemic vascular resistances during abdominal insufflation with $\mathrm{CO}_{2}$.

One of the potential limitations of the present study is related to the application of $\mathrm{CO}_{2}$ to inflate the abdomen while it is also being used as the tracer gas in the capnodynamic lung volume estimates. Although other gases can be used to produce pneumoperitoneum, ${ }^{2}$ $\mathrm{CO}_{2}$ is currently the most commonly used gas in routine clinical practice. Whether other inert gases would have less impact on the

TAB LE 1 Mean arterial pressure (MAP). Mean \pm half width of the $95 \%$ confidence interval

\begin{tabular}{lll}
\hline PEEP $\left(\mathrm{cm} \mathrm{H}_{2} \mathrm{O}\right)$ & IAP $(\mathrm{mm} \mathrm{Hg})$ & $\begin{array}{l}\text { MAP } \\
(\mathrm{mm} \mathrm{Hg})\end{array}$ \\
\hline PEEP3 & IAP0 & $52.1 \pm 9.3$ \\
& IAP6 & $64.3 \pm 18$ \\
& IAP12 & $69.1 \pm 27$ \\
\hline PEEP6 & IAPO & $55.8 \pm 16$ \\
& IAP6 & $76.2 \pm 11^{*}$ \\
PEEP9 & IAP12 & $77.0 \pm 13^{*}$ \\
& IAP0 & $62.4 \pm 22$ \\
& IAP6 & $71.9 \pm 17$ \\
\hline & IAP12 & $75.5 \pm 16^{*}$
\end{tabular}

Abbreviations: IAP, positive end expiratory pressure; PEEP, intraabdominal pressure.

${ }^{*} P<.05$ vs IAPO within a PEEP.
$E E L V_{\mathrm{CO}_{2}}$ estimation is a subject of future investigation. Another methodological concern is the choice of IAP and PEEP levels, but our aim was to limit the value of these variables within the clinically relevant ranges for pediatric practice.

The value of $\mathrm{LCl}$ as an indicator of lung homogeneity is another potential limitation of the study. $\mathrm{LCl}$ is not unaffected by changes in the tidal volume/EELV ratio which potentially could influence the $\mathrm{LCl}$ values since tidal volume was constant whereas EELV changed. It has, however, been suggested in previous studies that other factors than the ratio of TV/EELV, mainly small airway collapse and atelectasis formation, affects $\mathrm{LCl}$ even if the tidal volume is constant with increasing EELV. ${ }^{21,22}$ Nevertheless, $\mathrm{LCl}$ values measured under these conditions can only be regarded as approximate markers of lung homogeneity and their value as absolute indicators of even lung ventilation must be judged thereafter.

Finally, to stay within an acceptable time frame during the experiment, the duration of each step was limited to a much shorter period than would be encountered in clinical practice. However, the time interval used allowed for establishing steady state condition prior to starting the data collection during each study protocol permutation. In addition, there was no evidence for a systematic change in the subsequent data sets.

In conclusion, capnodynamic assessment of $\mathrm{EELV}_{\mathrm{CO}_{2}}$ only reflects $\mathrm{EELV}_{\mathrm{He}}$ if the increased IAP during capnoperitoneum is counteracted by enough PEEP to provide for EELV levels around normal values, associated with near-normal $\mathrm{LCl}$. Under these conditions, $\mathrm{EELV}_{\mathrm{CO}_{2}}$ showed $100 \%$ trending capacity compared to $\mathrm{EELV}_{\mathrm{He}}$.

\section{ACKNOWLEDGEMENTS}

Assistance with the study: The laboratory faculty and staff of the Unit for Anaesthesiological Investigations, Department of Acute Medicine, University of Geneva, Geneva Switzerland

\section{CONFLICTS OF INTEREST}

Jacob Karlsson received an unrestricted research grant from Maquet Critical Care AB. Mats Wallin and Magnus Hallbäck are employed by Maquet Critical Care AB. The other authors declare no conflict of interest.

\section{AUTHORS' CONTRIBUTIONS}

J. K., G. H. F., A. d. S. R., N. L., W. H., M. W., F. P., and P. -A. L.: were involved in study design, data collection, and analysis, and manuscript writing and critical revision of manuscript.

\section{ORCID}

Jacob Karlsson (iD https://orcid.org/0000-0003-2277-0092

Ferenc Peták iD https://orcid.org/0000-0001-6249-9327

Per-Arne Lönnqvist (iD https://orcid.org/0000-0002-8586-1429

\section{REFERENCES}

1. Chan IH, Tam PK. Laparoscopic inguinal hernia repair in infants and children: state-of-the-art technique. Eur J Pediatr Surg. 2017;27(6):465-471 
2. Yu T, Cheng Y, Wang X, et al. Gases for establishing pneumoperitoneum during laparoscopic abdominal surgery. Cochrane Database Syst Rev. 2017. https://doi.org/10.1002/14651858.CD009569. pub3

3. Wolf JS, Clayman RV, Monk TG, McClennan BL, McDougall EM. Carbon dioxide absorption during laparoscopic pelvic operation. $J$ Am Coll Surg. 1995;180(5):555-560.

4. Wittgen CM, Andrus CH, Fitzgerald SD, Baudendistel LJ, Dahms TE, Kaminski DL. Analysis of the hemodynamic and ventilatory effects of laparoscopic cholecystectomy. Arch Surg. 1991;126(8):9971000. discussion-1.

5. Andersson LE, Bååth $M$, Thörne $A$, Aspelin $P$, Odeberg-Wernerman $\mathrm{S}$. Effect of carbon dioxide pneumoperitoneum on development of atelectasis during anesthesia, examined by spiral computed tomography. Anesthesiology. 2005;102(2):293-299.

6. von Ungern-Sternberg BS, Hammer J, Schibler A, Frei FJ, Erb TO. Decrease of functional residual capacity and ventilation homogeneity after neuromuscular blockade in anesthetized young infants and preschool children. Anesthesiology. 2006;105(4):670-675.

7. Lachmann B. Open up the lung and keep the lung open. Intensive Care Med. 1992;18(6):319-321.

8. Albu G, Wallin M, Hallbäck M, et al. Comparison of static end-expiratory and effective lung volumes for gas exchange in healthy and surfactant-depleted lungs. Anesthesiology. 2013;119(1):101-110.

9. Karlsson J, Fodor GH, dos Santos Rocha A, et al. Determination of adequate positive end expiratory pressure level required for carbon dioxide homeostasis in an animal model of infant laparoscopy. Acta Anaesthesiol Scand. 2020; in press.

10. Albu G, Petak F, Zand T, Hallbäck M, Wallin M, Habre W. Lung volume assessments in normal and surfactant depleted lungs: agreement between bedside techniques and CT imaging. BMC Anesthesiol. 2014;14:64.

11. McNulty W, Usmani OS. Techniques of assessing small airways dysfunction. Eur Clin Respir J. 2014;1:25898.

12. Fuchs SI, Eder J, Ellemunter H, Gappa M. Lung clearance index: normal values, repeatability, and reproducibility in healthy children and adolescents. Pediatr Pulmonol. 2009;44(12):1180-1185.

13. Suarez-Sipmann F, Bohm SH, Tusman G. Volumetric capnography: the time has come. Curr Opin Crit Care. 2014;20(3):333-339.
14. Karlsson J, Winberg P, Scarr B, et al. Validation of capnodynamic determination of cardiac output by measuring effective pulmonary blood flow: a study in anaesthetised children and piglets. $\mathrm{Br} \mathrm{J}$ Anaesth. 2018;121(3):550-558.

15. Hällsjö Sander C, Lönnqvist P-A, Hallbäck M, et al. Capnodynamic assessment of effective lung volume during cardiac output manipulations in a porcine model. J Clin Monit Comput. 2016;30(6): 761-769.

16. Critchley LA, Lee A, Ho AM. A critical review of the ability of continuous cardiac output monitors to measure trends in cardiac output. Anesth Analg. 2010;111(5):1180-1192.

17. Larsson A, Jonmarker C, LindahI SG, Werner O. Lung function in the supine and lateral decubitus positions in anaesthetized infants and children. Br J Anaesth. 1989;62(4):378-384.

18. Sivan $Y$, Deakers TW, Newth CJ. Functional residual capacity in ventilated infants and children. Pediatr Res. 1990;28(5):451-454.

19. Ibañez J, Raurich JM. Normal values of functional residual capacity in the sitting and supine positions. Intensive Care Med. 1982;8(4):173-177.

20. Aksakal D, Hückstädt T, Richter S, et al. Comparison of femoral and carotid blood pressure during laparoscopy in piglets. J Pediatr Surg. 2012;47(9):1688-1693.

21. von Ungern-Sternberg BS, Petak F, Saudan S, et al. Effect of cardiopulmonary bypass and aortic clamping on functional residual capacity and ventilation distribution in children. J Thorac Cardiovasc Surg. 2007;134(5):1193-1198.

22. Grönkvist M, Bergsten E, Gustafsson PM. Effects of body posture and tidal volume on inter- and intraregional ventilation distribution in healthy men. J Appl Physiol (1985). 2002;92(2):634-642.

How to cite this article: Karlsson J, Fodor GH, dos Santos

Rocha A, et al. End-expiratory lung volume assessment using helium and carbon dioxide in an experimental model of pediatric capnoperitoneum. Acta Anaesthesiol Scand. 2020;64:1106-1113. https://doi.org/10.1111/aas.13607 